\title{
Sternotomy for esophagectomy: Is it worth the risk?
}

\author{
Sameer A. Hirji, MD, and Benjamin Wei, $\mathrm{MD}^{\mathrm{b}}$
}

\footnotetext{
From the ${ }^{\mathrm{a} D i v i s i o n}$ of Cardiac Surgery, Department of Surgery, Brigham and Women's Hospital, Harvard Medical School, Boston, Mass; and the ${ }^{b}$ Division of Cardiothoracic Surgery, University of Alabama, Birmingham, Ala. Disclosures: Authors have nothing to disclose with regard to commercial support.

Received for publication Aug 31, 2018; accepted for publication Sept 4, 2018; available ahead of print Oct 11, 2018.

Address for reprints: Benjamin Wei, MD, Division of Cardiothoracic Surgery, University of Alabama, 739 Zeigler Research Building, 703 19th St S, Birmingham, AL 35233 (E-mail: bwei@uab.edu).

J Thorac Cardiovasc Surg 2018;156:e221-2

$0022-5223 / \$ 36.00$

Copyright (C) 2018 Published by Elsevier Inc. on behalf of The American Association for Thoracic Surgery https://doi.org/10.1016/j.jtcvs.2018.09.001
}

In this issue of the Journal, Okamura and colleagues ${ }^{1}$ present an interesting and complex case of esophagectomy for cT2N1M0 squamous cell carcinoma in a 66-year-old patient with a remote history of right pneumonectomy for non-small cell lung cancer. The procedure entailed a combination of an upper mediastinal lymphadenectomy that was performed through a partial sternotomy and a laparoscopic transhiatal esophagectomy. This approach was chosen because the patient was not a candidate for definitive chemoradiation in view of the risk of toxicity to his remaining lung, although he did receive induction chemotherapy. ${ }^{1}$ Okamura and colleagues ${ }^{1}$ are to be applauded for their technical prowess in approaching this case, given the anatomical and adhesive challenges associated with the operation. There are only scattered reports highlighting this approach, and they demonstrate similar postoperative morbidity. $^{2,3}$

This case highlights a couple of concepts. First is that the pattern and extent of the lymph node dissection especially in the context of esophagectomy is still quite debatable but yet very relevant. ${ }^{4}$ Many contemporary studies have demonstrated the prognostic significance of the recurrent laryngeal nerve lymph node on cervical lymph node metastasis and subsequent postoperative survival. ${ }^{4,5}$ A complete lymphadenectomy of nodes harboring or thought to harbor cancer is therefore ideal from an oncologic perspective. Second, lymphadenectomy along the recurrent laryngeal nerves can be technically challenging; this is especially the case for patients with previous pneumonectomy because of thickened pleura, shifted mediastinum or trachea, and compensatory physiologic changes. The novelty in this scenario was the use of upper partial (backward L-shaped) sternotomy for cervical and mediastinal lymphadenectomy, which facilitated complete dissection and removal of the metastatic lymph node along the right recurrent laryngeal nerve.

Others have approached similar cases with mediastinoscopy-assisted esophagectomy, which could potentially offer a faster recovery and less morbidity. ${ }^{6}$

\section{References} 723-5.

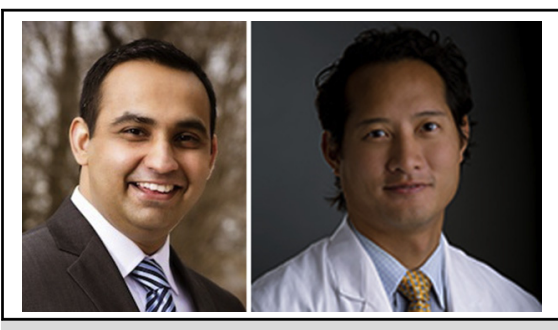

Sameer A. Hirji, MD (left), and Benjamin Wei, MD (right)

\section{Central Message}

Upper partial sternotomy for complete lymphadenectomy in patients with previous pneumonectomy should be performed after careful consideration of patient morbidity and overall oncologic outcome.

See Article page e217.

Also importantly, despite the technical success of this case, is the key question of whether this approach was worth the risk. Did adding the partial sternotomy and recurrent laryngeal nerve dissection improve the overall likelihood of survival for this patient? Although this patient was reported to be alive and well at 3 months, in lesser hands or with worse luck, the patient could have sustained recurrent laryngeal nerve injury leading to aspiration, pneumonia, need for tracheostomy, or death. Diving deeper into this case, questions arise. Could stereotactic radiosurgery to the culprit lymph nodes have played a role instead of lymphadenectomy ${ }^{7}$ How much riskier was definitive chemoradiation going to be than this surgery? Given the limited follow-up of this specific patient thus far, and the rarity of these cases, the oncologic benefit of such a tour-de-force is difficult to determine.

1. Okamura A, Watanabe M, Hayami M, Mine S. Esophagectomy via upper partial sternotomy for esophageal cancer after previous right pneumonectomy: a case report. J Thorac Cardiovasc Surg. 2018;156:e217-20.

2. Wang H, Liu J, Jiang C, Liu M, Jiang G. Transthoracic esophagectomy using endobronchial blocker after previous pneumonectomy. Ann Thorac Surg. 2014;97:

3. Velotta JB, Vasquez CR, Sugarbaker DJ. Transhiatal esophagectomy after previous right pneumonectomy. J Thorac Cardiovasc Surg. 2014;148:e150-2.

4. Shang QX, Chen LQ, Hu WP, Deng HY, Yuan Y, Cai J. Three-field lymph node dissection in treating the esophageal cancer. J Thorac Dis. 2016;8:E1136-49.

5. Ye K, Xu JH, Sun YF, Lin JA, Zheng ZG. Characteristics and clinical significance of lymph node metastases near the recurrent laryngeal nerve from thoracic esophageal carcinoma. Genet Mol Res. 2014;13:6411-9. 
6. Wang J, Wei N, Lu Y, Zhang X, Jiang N. Mediastinoscopy-assisted esophagectomy for T2 middle and lower thoracic esophageal squamous cell carcinoma patients. World J Surg Oncol. 2018;16:58.
7. Matzenauer M, Vrána D, Vlachová Z, Aujesky R, Vrba R, Neoral C, et al. Stereotactic radiotherapy in the treatment of local recurrences of esophageal cancer. Oncol Lett. 2017; 13:1807-10. 